\title{
EXAME COLPOCITOLÓGICO E AS POTENCIALIDADES E LIMITAÇÕES VIVENCIADAS POR MULHERES ${ }^{1}$
}

\author{
*Luciana Dantas Farias de ANDRADE ${ }^{2}$ \\ Ana Cláudia da Silva FERREIRA ${ }^{3}$ \\ Janaina von Söhsten TRIGUEIRO ${ }^{4}$ \\ Nathanielly Cristina Carvalho de Brito SANTOS ${ }^{5}$ \\ Maria Benegelania PINTO
}

\begin{abstract}
${ }^{1}$ Artigo extraído do Trabalho de Conclusão de Curso, intitulado - "Potencialidades e limitações do exame colpocitológico vivenciado por mulheres de um município paraibano" - apresentado ao Curso de Bacharelado em Enfermagem da Universidade Federal de Campina Grande, campus Cuité-PB, 2013.

${ }^{2}$ Enfermeira. Doutora em Psicologia. Professora da Unidade Acadêmica de Enfermagem, Universidade Federal de Campina Grande, Cuité-PB, Brasil.

${ }^{3}$ Bacharel em Enfermagem pela Universidade Federal de Campina Grande - UFCG. E-mail: claudinha12a@hotmail.com.

${ }^{4}$ Enfermeira. Doutoranda em Enfermagem pela Universidade Federal da Paraíba - UFPB. Docente na Universidade Federal de Campina Grande - UFCG, campus Cuité - PB. E-mail: janavs_23@ hotmail.com;

${ }^{5}$ Enfermeira. Doutoranda em Enfermagem pela Universidade Federal da Paraíba - UFPB. Docente na Universidade Federal de Campina Grande - UFCG, campus Cuité-PB. E-mail: nath-cris@ hotmail.com.

${ }^{6}$ Enfermeira. Mestre em Enfermagem pela Universidade Federal da Paraíba - UFPB. Docente na Universidade Federal de Campina Grande - UFCG, campus Cuité-PB. E-mail: benegelania@ yahoo.com.br.

* Email para correspondência: luciana.dantas.farias@gmail.com
\end{abstract}

Recebido em: 25/05/2015 - Aprovado em: 02/07/2015 - Disponibilizado em: 15/07/2015

\section{Resumo}

O Câncer de Colo do Útero é o terceiro tipo de câncer mais frequente e, diante das estratégias para diminuição das estatísticas considera-se que o melhor tratamento contra é a prevenção através do exame colpocitológico. Esta pesquisa objetivou conhecer as potencialidades e limitações que as mulheres atendidas nas estratégias saúde da família da zona urbana do município de Cuité, Paraíba, Brasil, demonstram em relação à realização do exame colpocitológico. Foi metodologicamente embasada no materialismo histórico e dialético através da visão de 15 clientes entrevistadas com roteiro semiestruturado. A análise do material empírico foi feita pela análise de discurso. Conclui-se que a maioria das mulheres entrevistadas ainda não entendem claramente o aspecto do rastreamento e prevenção do câncer de colo do útero, têm intrínseco em seu pensamento que a função principal do mesmo é o diagnóstico de alguma infecção ginecológica, embora o fato de realizarem o exame converge para um comportamento de autocuidado que favorece a qualidade de vida.

Palavras-chave: Atenção Primária à Saúde. Prevenção Primária. Enfermagem. Esfregaço vaginal. Neoplasias do Colo do Útero.

\section{SMEAR EXAMINATION AND THE POTENTIALITIES AND LIMITATIONS EXPERIENCED BY WOMEN}

\begin{abstract}
This article discusses an integrative literature review that aims to emphasize the importance of vocal health in different professional categories. The research was the type integrative literature review carried out from September to November 2014 in the search indexing databases SciELO and LILACS. The key words "speech" were used "voice" and "primary prevention" as orientation of Descriptors in Health Sciences of the Virtual Health Library to obtain articles involving the years 2003 to 2013 compiling eight articles. According to the articles analyzed can- to establish the existence of a considerable number of studies on the vocal health of teachers, while emphasizing the importance of further research to other professional categories that also make use of the voice as a working tool. We conclude that, in fact, teachers are the professionals who are most affected by disturbances in the vocal tract, although health professionals, lawyers, entertainers, among others also deserve specific studies in their areas. The presence of the speech therapist in primary health care favors the development of prevention/promotion of vocal health to the different professional categories.

Keywords: Primary health care. Primary Prevention. Nursing. Vaginal smears. Uterine Cervical Neoplasms
\end{abstract}




\section{Introdução}

O Câncer de Colo do Útero é o terceiro tipo de câncer mais frequente com aproximadamente 500 mil novos casos por ano no mundo, sendo responsável por cerca de 230 mil mortes em mulheres por igual período. Para o Brasil são esperados 15.590 casos novos no ano de 2014, com um risco estimado de 17 casos a cada 100 mil mulheres (BRASIL, 2014).

Com relação à incidência, o câncer de colo do útero tem suas taxas observadas em países pouco desenvolvidos, o que indica uma forte associação deste tipo de câncer com as precárias condições de vida, baixos índices de desenvolvimento humano, além da fragilidade ou ausência de estratégias envolvendo a educação comunitária (prevenção e promoção em saúde) como reflexo da dificuldade de acesso aos serviços públicos de saúde e a um diagnóstico precoce e tratamento das lesões precursoras em tempo hábil (BRASIL, 2011).

Além desses fatores, a multiplicidade de parceiros sexuais, tabagismo, início precoce da atividade sexual, higiene íntima inadequada e o uso prolongado de contraceptivos orais também contribuem para o aparecimento do câncer de colo uterino, embora o principal agente etiológico seja o vírus do papiloma humano (HPV) de transmissão sexual (NERI; et. al., 2013).

Indubitavelmente defende-se que o melhor tratamento contra o câncer de colo uterino é a prevenção. Nessa perspectiva, o
Brasil tem utilizado como principal estratégia a realização do Exame Colpocitológico ou exame Papanicolaou, que permite a detecção precoce dessa neoplasia.

Considerado prático e de custo acessível, este exame consiste na coleta de material da cérvice uterina, de onde se retiram amostras celulares da ectocérvice e da endocérvice visando uma análise histológica, mediante a coloração multicrômica de lâmina. É um método manual disponível na atenção pública primária à saúde e que pode ser realizado por profissionais da enfermagem, ou medicina, possibilitando a identificação de células sugestivas de pré-invasão e até lesões malignas (JORGE; et. al., 2011).

Diante do exposto, objetiva-se conhecer as potencialidades e as limitações que as mulheres atendidas nas estratégias saúde da família da zona urbana do município de Cuité, na Paraíba, Brasil, demonstram em relação à realização do exame colpocitológico.

\section{Material e Métodos}

O estudo foi realizado no município de Cuité, localizado no estado da Paraíba, Brasil, o qual oferece atendimento à população no âmbito da atenção pública primária e secundária à saúde. Como porta de entrada para a rede de atenção à saúde, o município conta com nove Estratégias Saúde da Família, sendo cinco localizadas na zona urbana e quatro na zona rural. Na atenção pública 
secundária inclui-se o hospital de médio porte denominado Hospital e Maternidade Municipal Nossa Senhora das Mercês.

Esta pesquisa foi desenvolvida com 15 mulheres devidamente cadastradas nas estratégias saúde da família da zona urbana, e que já utilizaram o serviço para realização do exame colpocitológico, sendo selecionadas três usuárias de cada estratégia saúde da família segundo esses critérios de inclusão. Dentre essas, fez-se necessário a assinatura do Termo de Consentimento Livre e Esclarecido (TCLE) concordando formal e voluntariamente a participar do estudo, após aprovação do projeto pelo Comitê de Ética em Pesquisa mediante parecer $\mathrm{N}^{\circ}$ 408.280. Para garantir o anonimato da participante, as entrevistadas foram identificadas pelo nome "Mulher" seguido do número crescente da entrevista.

Para coleta dos dados de enfoque qualitativo, utilizou-se um roteiro semiestruturado de entrevista contendo as seguintes questões norteadoras: 1 . O que você sabe sobre o exame colpocitológico? 2. Qual a sua relação com a enfermeira da estratégia saúde da família, profissional responsável pela realização do exame? 3. O que você sente quando se submete a esse exame? Todas as entrevistas foram gravadas e transcritas para posterior análise.

Os procedimentos para a realização da pesquisa incluíram três momentos: fase exploratória da investigação (realizada através do levantamento bibliográfico); trabalho de campo (realização das entrevistas no âmbito da estratégia saúde da família com a produção do material empírico) e análise do material empírico (utilização da técnica de análise de discurso proposta por Fiorin) (FIORIN, 2005).

A partir de contínuas leituras em busca das figuras (elementos concretos) e temas (elementos abstratos) foi possível formular as categorias empíricas. Em seguida, os temas principais foram compreendidos e os dados agrupados em blocos de significação que originou a categoria analítica, descrita na tabela 1 .

Tabela 1: Seleção das categorias

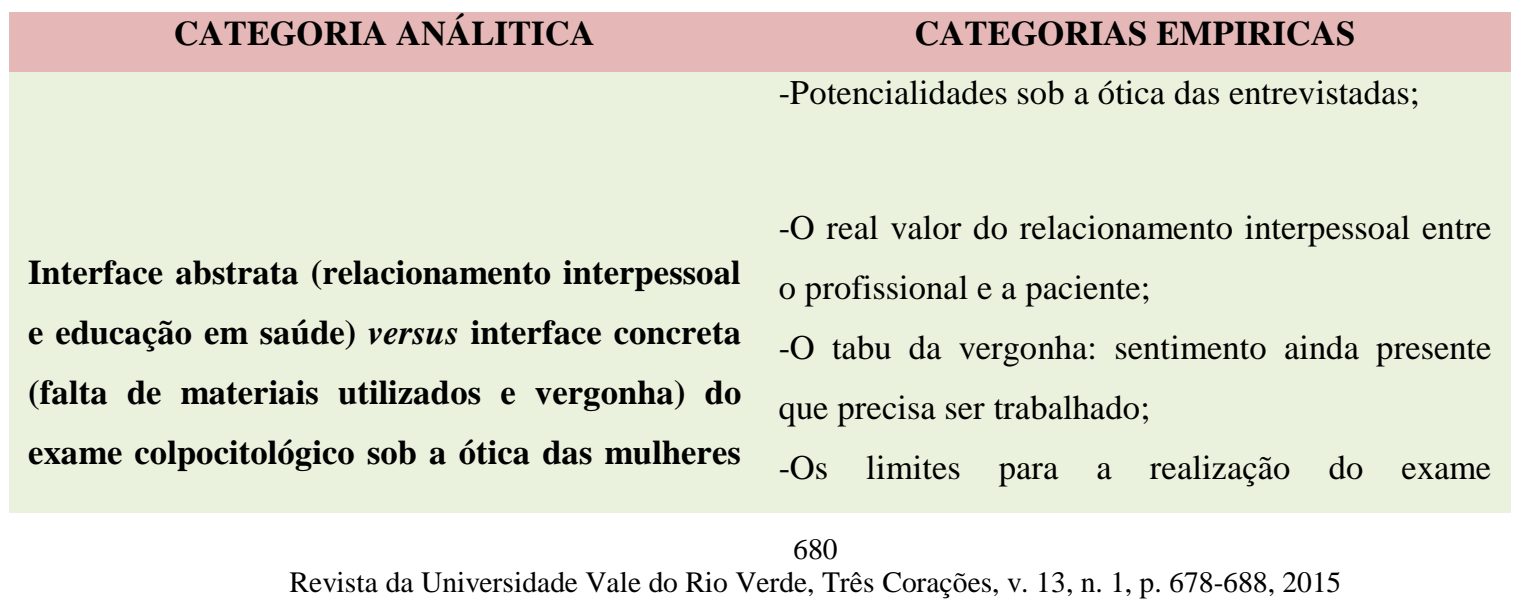


Fonte: Dados da pesquisa: 2013

\section{Resultados e discussão}

Quando as mulheres foram indagadas a respeito da realização do exame colpocitológico foi possível inferir as potencialidades sob a ótica das entrevistadas, pois a maioria relatou que o exame estava ligado à importância de descobrir alguma patologia, conforme é percebido nas falas: "Eu acho que é muito importante por que assim você vai se prevenir das doenças que poderão vir e você vai saber para poder se cuidar a tempo" (Mulher I); “Assim... é... eu acho importante porque você sabe realmente o que tem” (Mulher II); “É... o que eu sei é que é uma prevenção, né, fazer o exame, saber se tem alguma coisa... se cuidar!" (Mulher VIII).

Embora a assertiva em prevenir alguma infecção ginecológica demonstre convergência com o tema estudado é importante destacar que, das quinze mulheres que se submeteram à entrevista, apenas uma relatou que o exame seria uma maneira de prevenir contra o câncer do colo do útero consoante sua fala: "Legal, né, que é pra gente prevenir contra o câncer de útero" (Mulher IX).

Os aspectos educativos promovidos pelas campanhas incentivadas pelo Ministério da Saúde e desenvolvidas, principalmente, no âmbito das Estratégias Saúde da Família têm desencadeado um "falso" conhecimento acerca do objetivo principal de sua realização. Por muitas vezes, as mulheres associam a realização do exame colpocitólogico à detecção de afecções ginecológicas e não, especificamente, prevenção e rastreamento do câncer de colo uterino, como subsídio para o tratamento precoce e maiores chances de cura da doença (TEIXEIRA; PORTO; SOUZA, 2012).

Pode-se inferir que as atividades de educação em saúde, imprescindíveis nas campanhas de prevenção do câncer de colo do útero devem ser realizadas de maneira clara e acessível, de preferência com usufruto de abordagens lúdicas e relacionais, contrárias às tradicionais palestras expositivas em que o profissional de saúde detém todo o conhecimento, cabendo ao usuário do 
serviço o papel de expectador à adquirir toda informação repassada (CASARIN; PICCOLI, 2011).

A procura pela realização do exame colpocitológico pode depender do significado que ele representa para as mulheres, elaborado a partir da maneira como o profissional vai conduzir a relação de cuidador e orientador para com elas (JORGE; et. al.; 2011).

Isso fica evidenciado na fala: "Por eu não ter muita conversa com ela eu fico mais encabulada ainda, né, de ir e ter que fazer!" (Mulher V).

Pelos profissionais de enfermagem, estarem de certa forma, mais próximos da população no que diz respeito ao contexto familiar, devem construir vínculos de confiança para que ocorram estímulos à discussão e esclarecimentos de diversos temas. No que concerne à importância da prevenção do câncer de colo uterino faz-se necessário formas alternativas que busquem compreender cada mulher individualmente (RIBEIRO; et. al., 2013).

Contrária a essa realidade, usuárias atendidas em outras estratégias saúde da família relataram manter um bom relacionamento interpessoal com as enfermeiras que as assistem: "É boa, ela conversa, ela é bacana!" (Mulher VII); "É boa, não tenho nada a reclamar, não” (Mulher VIII); “Ela conversa, fala que sempre tem que fazer o exame" (Mulher X).

Com as duas faces apresentadas neste estudo, acerca do relacionamento estabelecido nas consultas realizadas nos serviços de saúde, alerta-se para que ocorra um maior aprofundamento na capacitação da Enfermagem Humanística, pois é pela comunicação que as transformações vão ocorrer nos momentos da vida do ser humano ao construir sua história (NERI; et. al., 2013).

Nesse sentido, percebe-se a necessidade de que o profissional que atua na atenção à mulher durante o exame preventivo do câncer de colo uterino tenha atributos como empatia, calor humano, simplicidade, e que possa ser capaz de transmitir para as suas clientes aspectos como segurança e confiança. Esse deve ainda, estar atento às duvidas, queixas e ansiedades dessa mulher, desenvolvendo a capacidade de interagir, esclarecer e despertar o interesse das usuárias por informações, principalmente no que diz respeito à situação e manutenção dos cuidados com sua saúde (DIÓGENES; et. al., 2011). 
Quando questionadas a respeito do sentimento vivenciado quando pensavam em se submeter à realização do exame colpocitológico, a maioria relatou que sentia vergonha: "Na mente né? Sentimento vergonhoso, né, a gente é muito 'vergonheta', eu mesmo sou muito 'vergonheta' pra fazer, pra fazer esse exame, muito mesmo, eu fiz por que tinha que fazer... com medo de... né” (Mulher II); "Vergonha! Eu fico com vergonha, né! Por que, assim, é constrangedor, né, está ali, sabe que é uma mulher, mas você fica com vergonha"; (Mulher IV); "(risos) vergonha por que não tem ninguém que não sinta, né!" (Mulher VI); “Eu sinto vergonha, com toda certeza!” (Mulher VIII).

A naturalização dos papéis masculinos e femininos na coletividade reforça a ideologia do lugar que a mulher ocupa no contexto socioeconômico e cultural a qual está inserida, como secundário e menos valorizado. A imposição de inexistência da mulher como sujeito social ativo, expressa durante séculos, desencadeou outras formas de invisibilidade, inclusive, sobre a relação com seu corpo e o cuidado com a própria saúde, seu sexo e sua sexualidade (ANDRADE; et. al., 2013).

As mulheres relataram sentir constrangimento por ter o seu corpo manipulado e exposto, mesmo que essa exposição seja feita diante de um profissional habilitado: "Por que é constrangedor, né, está ali, sabe que é uma mulher, mas você fica com vergonha!" (Mulher I); “É vergonha, vergonha demais mesmo, o 'caba' se expondo ali, pois a mulher é bicho ‘vergonhento’!” (Mulher II).

Sendo o exame Papanicolau pertencente exclusivamente ao universo feminino, cada mulher tem sua própria opinião sobre o exame. Os julgamentos expostos por elas em relação a esse procedimento vão interferir diretamente no comportamento ao serem submetidas ao exame colpocitológico e, assim, os sentimentos gerados são vivenciados de forma única (ANDRADE; et. al., 2013).

Quando perguntadas a respeito das limitações para realizarem o exame colpocitológico algumas mulheres relataram a falta de material identificada à ida ao serviço, ou antes disso, por meio de informações repassadas por outras clientes/pacientes: "Já, às vezes falta material. É, tem delas que não querem voltar, ficam chateadas, mas 
tem outras que vão ainda!" (Mulher XIX); "Teve uma vez que eu fui três vezes marcar e não dava, podia ter o material, disseram que não tinha, como se diz, dizia sempre que estava faltando o material, alguma coisa porque eu ia e nunca dava certo... três vezes!" (Mulher VII); “Não, eu já fui lá duas vezes é está faltando... não tem o material!" (Mulher VI); “Não, não tem! eu digo pela minha irmã desde a campanha que teve, ela ia para fazer e voltava... ia não sei quantas vezes!” (Mulher V).

As dificuldades enfrentadas pela unidade de saúde com relação aos recursos materiais são apontadas como causalidade para a não realização do exame colpocitológico conduzindo inevitavelmente à desistência (ANDRADE; et. al, 2013).

Apesar dos relatos encontrados entre as mulheres de duas estratégias saúde da família, faz-se imprescindível destacar que as outras entrevistadas dos demais serviços não relataram a ausência de material para a submissão ao exame como aspecto limitador, o que leva a crer que algumas unidades sejam melhor abastecidas em termos de recursos materiais para realização do exame colpocitológico em detrimento a outras.
Indagou-se o conhecimento das mulheres no que diz respeito à técnica $\mathrm{e}$ aos materiais utilizados para realização do exame, a fim de analisar se os profissionais de enfermagem realizavam atividades de educação em saúde abordando o procedimento de maneira clara e objetiva, como subsídio para esclarecer à mulher sobre a relevância do mesmo para sua saúde e fortalecer a adesão à prevenção desse câncer.

Algumas entrevistadas não conheciam a técnica utilizada, bem como os materiais necessários para a realização do exame colpocitológico, inclusive não detinham a atenção necessária para essa informação: "Sei direito, não!” (Mulher IV); “Não tenho conhecimento, não" (Mulher V); "Não, não conheço" (Mulher VI)”; “Eu nunca presto atenção!” (Mulher X).

Embora a situação exposta por parte das entrevistadas revele $o$ desconhecimento acerca do procedimento, é importante elucidar a declaração "Eu nunca presto atenção!" da Mulher X. O fato de não expressar nenhuma preocupação com relação ao procedimento realizado converge para um comportamento de vulnerabilidade que aumenta os índices estatísticos do câncer de colo do útero. 
A vulnerabilidade individual refere-se ao grau e à qualidade da informação de que os indivíduos dispõem, à capacidade de interpretar tais informações e incorporá-los aos seus repertórios cotidianos. Desta forma, ratifica-se a assertiva de que as condições culturais, econômicas e políticas precisam ser consideradas, principalmente no que concerne à implementação de atividades de promoção à saúde e prevenção de agravos (PIMENTEL; et. al, 2011).

Contrário a esse posicionamento, outras entrevistadas referiram conhecer a técnica, bem como os materiais utilizados durante a realização do exame, como em seus depoimentos: “Conheço, sim!” (Mulher VIII); "Sim, conheço as etapas e os materiais" (Mulher XII); "Conheço, tem os espéculos que são temidos pelas mulheres que algumas relatam que machucam, que dói, que arde, tem uns que são de aço, os de plástico são mais utilizados” (Mulher XII).

Pode-se inferir que há uma significativa diferença entre as participantes do estudo que são assistidas nas cinco estratégias de saúde do Município de Cuité, Paraíba, no que diz respeito ao conhecimento da técnica e dos materiais utilizados para a realização do exame. Ressalta-se o grau e a qualidade da informação oferecida às entrevistadas assistidas pela atenção primária à saúde do município.

Sentimentos de medo, receio e tabus podem está retardando a procura pelos serviços de saúde por não terem obtido adequadamente informações sobre a importância da realização de exames preventivos, ou ainda, se receberam tiveram dificuldade para elaborá-las, vergonha em esclarecê-las e, sobretudo, incorporá-las em seu cotidiano de preocupações.

Além das limitações no aspecto subjetivo das usuárias do serviço, existem ainda as deficiências nos modelos de assistência e, sobretudo, na humanização do atendimento, grau de compromisso e qualidade das instituições, dos recursos materiais e estruturais, do gerenciamento e monitoramento dos programas de prevenção e detecção do câncer do colo do útero.

\section{Conclusão}

Analisando a temática envolvendo o exame colpocitológico foi possível perceber que se trata de uma importante ferramenta no que diz 
respeito à prevenção, diagnóstico e tratamento precoce do câncer do colo do útero. As estatísticas vêm demostrando que esse tipo de câncer ainda continua sendo um dos tipos de câncer que mais causa mortes na população feminina, inferior apenas ao câncer de mama e de cólon e reto.

A realização deste estudo possibilitou a constatação de que a maioria das mulheres entrevistadas e que se submeteram ao exame colpocitológico ainda não entendem claramente o aspecto do rastreamento e prevenção do câncer de colo do útero, tendo intrínseco em seu pensamento que a função principal do mesmo é o diagnóstico de alguma infecção ginecológica.

A simples consulta a alguma afecção ginecológica desvia a atenção do debate sobre as neoplasias que possam existir nas famílias destas mulheres. $\mathrm{O}$ fato de realizarem o exame converge para um comportamento de autocuidado em relação à saúde da mulher, embora negligencie a investigação para outros possíveis cânceres, dependendo do histórico de cada mulher.

A importância em praticar atividades de educação em saúde de forma intensa e com um enfoque mais individual por parte dos profissionais da enfermagem que prestam assistência às mulheres nas estratégias saúde da família ficou evidente quando comparado à segurança demonstrada pelas pacientes que mantêm um bom relacionamento interpessoal acerca da técnica e dos materiais necessários para a realização do exame colpocitológico.

A reflexão sobre a temática deve ser aprofundada para que seja discutido com a comunidade os comportamentos de risco que conduzam ao câncer, mais especificamente ao câncer de colo do útero, a importância da prevenção mediante a consciência da realização periódica do exame colpocitológico e o tratamento para o diagnóstico precoce.

São muitos os desafios a serem enfrentados na busca pela redução das morbimortalidades associadas ao câncer de colo uterino, neste contexto merece destaque o aumento das atividades de educação permanente e educação continuada aos profissionais de saúde, além de atividades educativas à saúde da mulher. As informações à população contribuem para adoção consciente de comportamentos convergentes com a prevenção de agravos, o que vai 
possibilitar uma melhor qualidade de vida.

\section{Referências}

1 ANDRADE, S. S. C; et. al.

Compreensão de usuárias de uma

unidade de saúde da família sobre o exame Papanicolaou. Ciência \& Saúde

Coletiva. n. 18, v. 8: 2301-10, 2013.

2 CASARIN, M. R.; PICCOLI, J. C. E.

Educação em saúde para prevenção do câncer de colo do útero em mulheres do município de Santo Ângelo/RS. Ciência \& Saúde Coletiva. n. 16, v. 09:39253932, 2011.

3 Diógenes MAR, et. al. Barreiras à realização periódica do Papanicolau: Estudo com Mulheres de uma Cidade do Nordeste do Brasil. Rev. APS. Jan/Mar, n. 14, v. 1:12-18, 2011.

5 FIORIN, J. L. Elementos de análise de discurso. São Paulo: ContextoEdusp, 2005.

6 JORGE, R. J. B.; et. al. Exame Papanicolau: sentimentos relatados por profissionais de enfermagem ao se submeterem a esse exame. Ciência \&
Saúde Coletiva. n. 16, v. 5:2443-51, 2011.

7 BRASIL. Ministério da Saúde (BR), Instituto Nacional de Câncer (INCA), INA e Ministério da Saúde apresentam estimativas de câncer para 2014. 2014. Disponível em: http://www2.inca.gov.br/wps/wcm/conn ect/agencianoticias/site+/home+/noticia s/2013/inca_ministerio_saude_apresenta m_estimativas_cancer_2014. Acesso em 27 Jan 2014.

8 BRASIL. Ministério da Saúde (BR), Instituto Nacional de Câncer (INCA), Coordenação Geral de Ações Estratégicas. Divisão de Apoio à Rede de Atenção Oncológica. Diretrizes brasileiras para o rastreamento do câncer do colo do útero. Rio de Janeiro: INCA, 2011.

9 NERI, E. A. R.; et. al. Conhecimento, atitude e prática sobre o exame papanicolaou de prostitutas. Texto Contexto Enferm. Jul-Set, n. 22, v. 3:731-8, 2013.

10 PIMENTEL, A. V.; et. al. A percepção da vulnerabilidade entre mulheres com diagnóstico avançado do 
câncer do colo do útero. Texto

Contexto enferm. Abr-Jun, n. 20, v.

2:255-62, 2011.

11. RIBEIRO, K. F. C.; et. al.

Conhecimento, atitude e prática de

acadêmicas de enfermagem sobre o

exame papanicolaou. Texto Contexto

Enferm. Abr-Jun, n. 22, v. 2:460-7, 2013.

12 TEIXEIRA, L. A; PORTO, M. A.

T.; SOUZA, L. P. A. A expansão do

rastreio do câncer do colo do útero e a

formação de citotécnicos no Brasil.

Physis. Revista de Saúde Coletiva. n.

22, v. 2:713-31, 2012. 